\title{
Ten-year adherence to continuous positive airway pressure treatment in patients with moderate-to-severe obstructive sleep apnea
}

\author{
Matsusato Tsuyumu ${ }^{1,2}$ (D) $\cdot$ Tadao Tsurumoto $^{1} \cdot$ Jiro limura $^{1} \cdot$ Tsuneya Nakajima $^{1} \cdot$ Hiromi Kojima $^{2}$
}

Received: 3 July 2019 / Revised: 28 January 2020 / Accepted: 5 February 2020 / Published online: 19 February 2020

(C) The Author(s) 2020

\begin{abstract}
Purpose This study aimed to evaluate the 10-year adherence to and identify the predictors of dropout from continuous positive airway pressure (CPAP) treatment for patients with moderate-to-severe obstructive sleep apnea (OSA).

Methods We retrospectively analyzed the continuity, dropout, or other behaviors of 181 patients who initiated CPAP treatment at the Tokyo Dental College Ichikawa General Hospital from January 2003 to June 2005.

Results Among a total of 181 patients, 56 (30.9\%) dropped out of the treatment. Among the 125 patients who did not dropout, 54 continued CPAP treatment for $>10$ years, 16 completed the treatment with OSA improvement, and 7 could not complete the treatment owing to unavoidable reasons such as death, dementia, hospitalization for serious illness, or migration to other countries. Further, 47 patients moved to another facility, whereas 1 patient purchased a CPAP device and stopped visiting our facility. Among the 56 patients who dropped out, approximately 50\% of the patients dropped out within a year, and all dropped out within 76 months. Comparing demographics, OSA parameters, and CPAP parameters between the patients who did and did not drop out of the treatment, Cox regression analysis indicated that body mass index (BMI) and the first-month utilization rate were clinical variables that were independently associated with discontinuation of CPAP treatment.

Conclusion The results of this study show that BMI and the first-month utilization rate of CPAP treatment are the predictors of the long-term adherence to this treatment.
\end{abstract}

Keywords Obstructive sleep apnea $\cdot$ Polysomnography $\cdot$ Body mass index $\cdot$ First-month utilization rate $\cdot$ Long-term continuation $\cdot$ Continuous positive airway pressure

\section{Introduction}

Obstructive sleep apnea (OSA) is a very common respiratory disorder that is estimated to affect 936 million individuals aged $30-69$ of the worldwide population [1]. OSA leads to

Electronic supplementary material The online version of this article (https://doi.org/10.1007/s11325-020-02033-0) contains supplementary material, which is available to authorized users.

Matsusato Tsuyumu tsuyumu@jikei.ac.jp

1 Department of Otorhinolaryngology, Tokyo Dental College Ichikawa General Hospital, Chiba, Japan

2 Department of Otorhinolaryngology, Jikei University School of Medicine, 3-25-8 Nishi-shimbashi, Minato-ku, Tokyo 105-8461, Japan an increase in metabolic diseases, neurological disorders, cardiovascular diseases, and mortality rates [2-4].

Continuous positive airway pressure (CPAP) improves subjective symptoms, such as daytime sleepiness, cognitive performance, blood pressure, and quality of life [5-9]. Longterm prognosis is affected by adherence to CPAP treatment rather than OSA severity [10].

CPAP treatment's one- [11, 12], 2- [13], and 3-year continuation rates [14] have been reported; however, CPAP treatment should be continued for longer than 3 years. Although long-term continuation studies have been conducted [15-23], in many studies, it is not clear as to how many years are considered long term. Although we considered that "10 years" was a relatively long period of time, few reports analyzed in detail whether patients with OSA continued CPAP treatment, dropped out of CPAP, or followed other courses for a long period of 10 years after CPAP was initiated. The purpose of this study was to retrospectively examine the progress 10 years 
after the start of CPAP and to investigate factors related to its continuation/omission, while targeting patients with OSA who started CPAP more than 10 years ago.

\section{Methods}

\section{Patients}

Overall, 280 patients suspected of OSA underwent polysomnography (PSG) with hospitalization at the Tokyo Dental College Ichikawa General Hospital for the first time from January 2003 to June 2005. In Japan, CPAP treatment for patients with OSA with an apnea-hypopnea index (AHI) of $\geq 20 / \mathrm{h}$ is covered by government health insurance. As per the results of PSG, 196 patients had an AHI of $\geq 20 / \mathrm{h}$. In this study, we provided CPAP treatment to 181 patients. In accordance with the Japanese health care system, all patients using CPAP treatment were required to visit medical institutions every month to report their usage.

All PSG and CPAP titrations in the facility were conducted using the Alice4 system (Philips, Respironics Inc., Murrysville, PA, USA). All PSG were manually analyzed according to the standard criteria [24]. Apnea was defined as a lack of airflow that lasted for $>10 \mathrm{~s}$. Hypopnea was defined as a decrease in the airflow by approximately $50 \%$ for at least $10 \mathrm{~s}$ or a decrease of $3 \%$ in oxygen saturation [25]. Moreover, 181 patients underwent CPAP titration on the second night of hospitalization using an automatic CPAP device under the supervision of skilled staff. When a significant increase in pressure was observed, the pressure was adjusted by the staff. A pressure range was obtained to normalize the breathing pattern and minimize arousals. After the titration test, automatic CPAP treatment was provided to the patient.

\section{Procedures}

\section{Investigation of CPAP continuation}

CPAP application (the number of days that CPAP was used by patients with OSA at their home in 1 month) was confirmed every month. A memory card in the CPAP device recorded the days on which CPAP was used and not used. We recorded the number of days of CPAP use for each patient. Patients who reported difficulty in CPAP application owing to nasal closure symptoms were treated with a nasal steroid to be used topically or an oral anti-allergy agent. For patients who complained of discomfort during use, the pressure was adjusted and the mask type was changed. For patients who still wished to drop out of CPAP treatment, we also recommended other methods such as oral appliances or surgery. On the contrary, among the patients who continued CPAP for improving OSA, those who exhibited decreased obesity owing to diet and exercise therapy or underwent surgery for OSA were examined by conducting PSG again. Patients with an AHI decreased to $<20 /$ h were withdrawn from CPAP. Patients with AHI of $\geq 5 / \mathrm{h}$ but $<20$ / $\mathrm{h}$ discontinued CPAP according to the Japanese health care system and switched to treatment with the oral appliance. Patients with AHI of $<5 / \mathrm{h}$ were considered to have sufficiently improved OSA and discontinued treatment.

CPAP treatment was terminated following the death of patients or following difficulty of use due to dementia. Some patients faced difficulties in visiting our facility owing to serious illnesses requiring long-term hospitalization. In addition, some patients had to stop using CPAP under the Japanese health care system due to overseas migration.

Patients who were no longer able to visit our facility owing to relocation within Japan decided to continue CPAP treatment under the Japanese health care system and visit hospitals located near their current location. Therefore, the subsequent use of CPAP treatment is unknown.

Adherence to CPAP 10 years after its initiation was defined and roughly classified into the following two categories.

Patients refusing CPAP: Patients who refused and dropped out of CPAP treatment. These patients underwent CPAP treatment and were instructed to use it, but later, they did not wish to continue CPAP or did not use CPAP at all.

Patients accepting CPAP: Patients who used CPAP treatment and did not dropout of CPAP treatment under our observation. This group was further classified as follows:

Continuation: Patients who continued CPAP treatment for $>10$ years. The following two points were considered necessary for continuing CPAP treatment: (1) those who wished to continue using CPAP treatment and (2) those who continued to visit our facility once a month.

Withdrawal: AHI decreased owing to events such as weight loss and/or surgery, and CPAP was determined to be unnecessary. Depending on the AHI, some of the patients switched to treatment with the oral appliance and others completed treatment with OSA.

Termination: CPAP was terminated owing to unrelated complications or inevitable reasons, such as death, advanced dementia, serious illness, or emigration.

Transfer to another facility: Patients decided to continue CPAP at another facility instead of ours.

CPAP self-management: One patient refused to visit our medical facility and purchased a CPAP device for OSA selfmanagement.

\section{Period until the dropout of CPAP treatment}

Regarding patients refusing CPAP, the period from the initiation of CPAP treatment to its discontinuation was summarized. The continuation rate of 10 years was evaluated according to the Kaplan-Meier survival analyses, and the number of 
months required for the continuation rate to reach the plateau was estimated.

\section{Factors related to the dropout of CPAP treatment}

Each patient's clinical background, OSA parameters obtained from PSG, and parameters obtained from CPAP titration were evaluated to determine the relationship between adherencerelated events and the following clinical background parameters: sex, age, body mass index (BMI), lifestyle (smoking and drinking habits), Epworth Sleepiness Scale (ESS) before the initiation of CPAP, nasal airflow resistance before the initiation of CPAP, and the first-month utilization rate, which is the ratio (percentage) of the days using CPAP to the days from the day of initiation of CPAP to the outpatient visit date 1 month later. Furthermore, we investigated AHI, apnea index, hypopnea index, minimum oxygen saturation $\left(\mathrm{SaO}_{2}\right)$, and time spent with $\mathrm{SaO}_{2}<90 \%$ measured using PSG and CPAP titration.

A univariate Cox regression analysis was performed to investigate the association between the dropout of CPAP treatment and the clinical background of the patients, parameters obtained by PSG or CPAP titration, and factors that were added after CPAP was initiated.

A Cox multivariate analysis was performed for each factor that was found to affect dropout from CPAP treatment with $p<0.1$ in univariate analysis. AHI is an important factor that indicates the severity of OSA and was thus entered into a multivariate analysis regardless of the results of univariate analysis. The assumption of proportional hazards was graphically verified using a log-log survival curve. The results of Cox multivariate analysis were expressed as the risk ratio with 95\% confidence interval, and $p<0.05$ was considered statistically significant. This research was approved by the Tokyo Dental University Ethics Committee.

\section{Results}

The baseline characteristics (sex, age, BMI, smoking and alcoholic status, ESS, and nasal airflow resistance) of the 181 patients included in the study have been summarized in Table 1.

\section{A 10-year course following the initiation of CPAP treatment in patients}

Overall, 56 patients (30.9\%) refused CPAP treatment and dropped out. Among the remaining 125 patients (69.1\%) who did not dropout of CPAP treatment, 54 continued CPAP treatment for $>10$ years, 16 completed the treatment with OSA improvement, and 7 could not complete the treatment owing to unavoidable reasons such as death, dementia, hospitalization for serious illness, or migration to other countries.
Table 1 Baseline characteristics of the 181 patients in the study

\begin{tabular}{|c|c|}
\hline Sex (male/female) ${ }^{\mathrm{a}}$ & $163 / 18(90.1 / 9.9)$ \\
\hline Age (years) ${ }^{b}$ & $48(37-60)$ \\
\hline BMI $\left(\mathrm{kg} / \mathrm{m}^{2}\right)^{\mathrm{b}}$ & $27.4(24.6-30.6)$ \\
\hline Smoke $\left(\right.$ yes/no) ${ }^{\mathrm{a}}$ & $66 / 115(36.5 / 63.5)$ \\
\hline Drink alcohol (yes/no) ${ }^{\mathrm{a}}$ & $105 / 76(58.0 / 42.0)$ \\
\hline $\mathrm{ESS}^{\mathrm{b}}$ & $8(5-10)$ \\
\hline Nasal airflow resistance $\left(\mathrm{Pa} / \mathrm{cm}^{3} / \mathrm{s}\right)^{\mathrm{b}, \mathrm{c}}$ & $0.571(0.364-1.180)$ \\
\hline
\end{tabular}

${ }^{a}$ Sex, smoking, and drinking are indicated by the number of cases (\%)

${ }^{\mathrm{b}}$ Age, BMI, ESS, and nasal airflow resistance are indicated by the median (interquartile range)

${ }^{\mathrm{c}}$ Nasal airflow resistance was measured as $\Delta \mathrm{P} 100 \mathrm{~Pa}$ during spontaneous nasal inspiration breathing using anterior rhinomanometry with the patient in a supine position

$B M I$ body mass index, ESS Epworth Sleepiness Scale

Further, 47 patients moved to another facility, and 1 purchased a CPAP device and stopped visiting our facility (Fig. 1).

\section{Period until the dropout of CPAP treatment}

The median duration from the initiation of CPAP treatment to its dropout was 12 (interquartile range (IQR) 4.5-21.5) months. Approximately half of the dropout patients discontinued CPAP treatment within 12 months of its initiation. The median duration from the initiation of CPAP treatment to its withdrawal with was 11.5 (IQR 6.5-14.5) months and to its termination with was 37 (IQR 18.5-87.8) months. The longest duration until dropout was 76 months (Fig. 2a). Eight (14.3\%) out of 56 patients underwent other treatments, such as that involving oral appliances or surgery, whereas the remaining patients refused treatment for OSA. To calculate the 10 -year retention rate, withdrawal, termination, transfer to another facility, and CPAP self-management groups were considered "censored" variables. It was estimated that $63.3 \%$ of the patients continued CPAP for 10 years according to the Kaplan-Meier method and that the proportion of the patients who continued CPAP treatment reached a plateau in nearly 76 months (Fig. 2b).

\section{Factors related to the dropout of CPAP treatment}

Based on the results of univariate analysis, the BMI of patients accepting CPAP was significantly higher than that of patients refusing CPAP. The first-month utilization rate after the initiation of CPAP treatment was significantly higher for patients accepting CPAP than for patients refusing CPAP. There was no statistical difference between sex, age, smoking habits, drinking habits, ESS, or nasal airflow resistance between the two groups (Table 2).

A low minimum $\mathrm{SaO}_{2}$ value measured by PSG was associated with CPAP treatment continuation, as observed in the results of PSG $(p<0.1)$ (Table 3$)$. 
Fig. 1 Flow diagram of study participants. OSA, obstructive sleep apnea; CPAP continuous positive airway pressure; AHI apnea-hypopnea index; PSG polysomnography

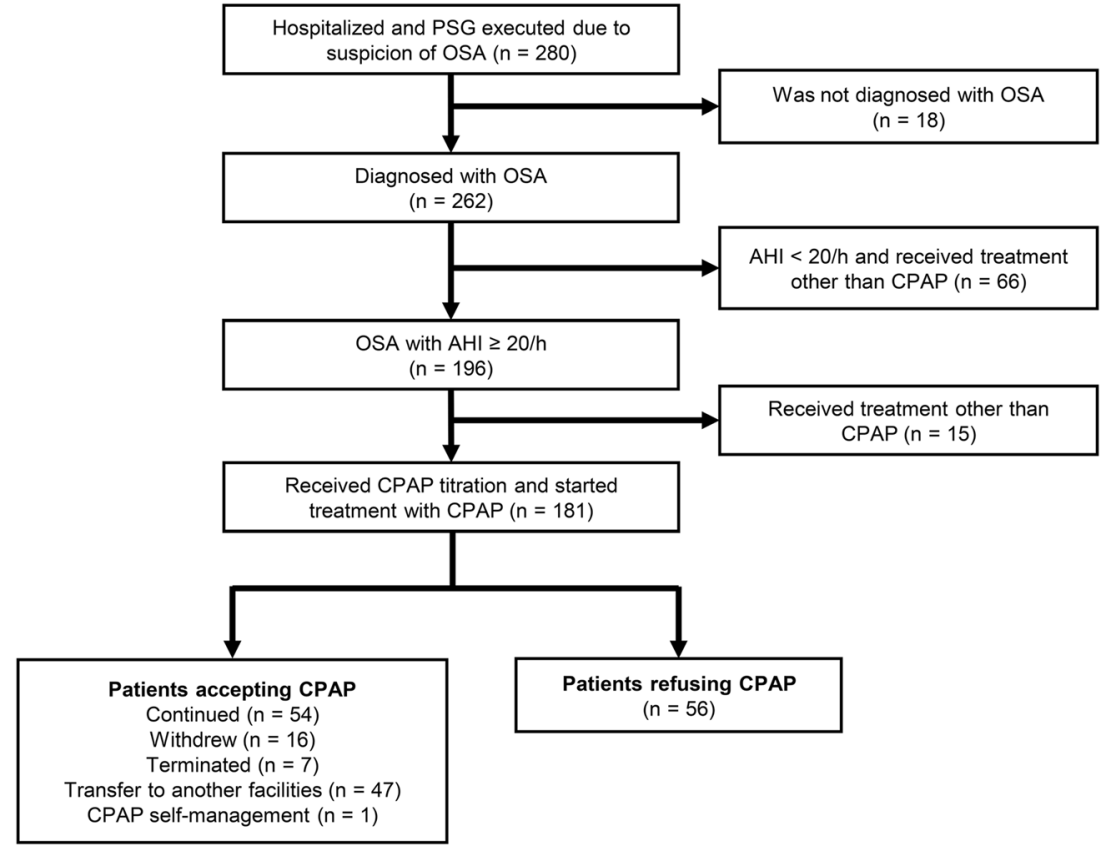

There was no statistical difference between the two groups with regard to OSA parameters obtained by CPAP titration (Table 4).

Factors with $p<0.1$ in univariate analysis and AHI were included in multivariate analysis. The Cox multivariate analysis was performed, and it was indicated that BMI $(p<0.001)$ and the first-month utilization rate $(p<0.001)$ were significantly associated with CPAP continuation for over 10 years (Table 5).

\section{Discussion}

This study evaluated factors affecting the continuation and dropout of CPAP treatment 10 years after its initiation in patients with OSA. Less than half of the patients $(30.9 \%)$ dropped out of the treatment. The withdrawal, termination, transfer to another facility, and CPAP self-management groups were considered censored cases, and the 10-year continuation rate was estimated to be $63.3 \%$ as per the Kaplan-Meier method. Patients refusing CPAP treatment discontinued it within 76 months from its initiation. Based on the results of multivariate analysis, BMI and first-month utilization rate immediately after the initiation of CPAP treatment were associated with the continuation of CPAP treatment.

In previous studies, the 10 -year continuation rate was estimated to be $64.1 \%$ [16], $70 \%$ [22], or $79.9 \%$ [23]. Compared with the previous predictions, the number of patients who dropped out was high and the number of those who continued CPAP treatment was low. The reason for this difference may be the differences in approaches across hospitals and countries. The number of patients who fail to continue treatment after being diagnosed with OSA may be higher than that predicted in the past.

In a previous study, no patient dropped out of CPAP treatment after 48 months from its initiation [19]. In the present study, the dropout was confirmed within 76 months. It should a

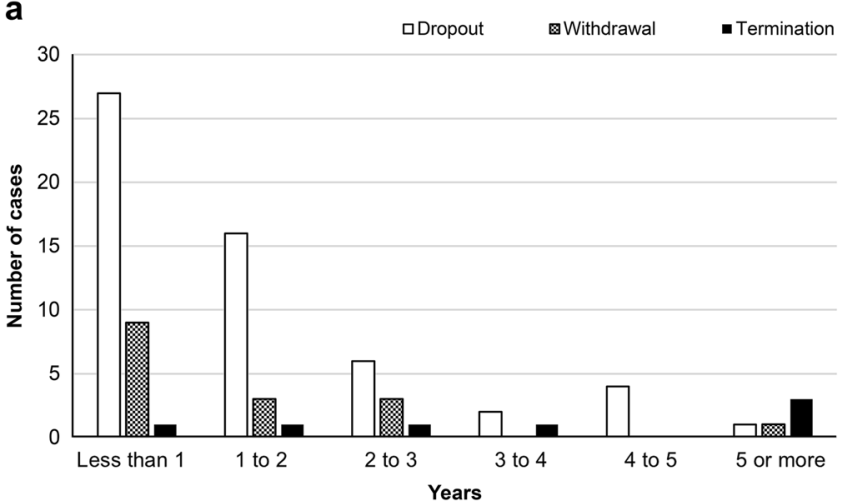

b

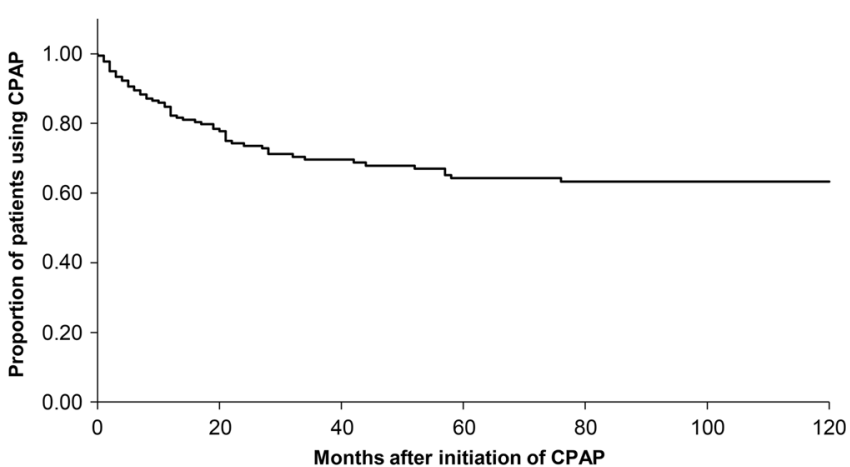

Fig. 2 a Number of years/patients until discontinuation in cases of patients refusing CPAP. b Kaplan-Meier curve presenting the proportion of patients on CPAP therapy versus time 
Table 2 Univariate analysis: Variables affecting dropout of CPAP (clinical background)

\begin{tabular}{|c|c|c|c|c|}
\hline & $\begin{array}{l}\text { Patients refusing } \\
\text { CPAP }(n=56)\end{array}$ & $\begin{array}{l}\text { Patients accepting } \\
\text { CPAP }(n=125)\end{array}$ & $\begin{array}{l}\text { Hazard ratio } \\
(95 \% \mathrm{CI})\end{array}$ & $P$ value \\
\hline Sex: male/female ${ }^{a}$ & $50 / 6(89.3 / 10.7)$ & $113 / 12(90.4 / 9.6)$ & $0.87(0.37-2.02)$ & 0.746 \\
\hline Age (years) ${ }^{\mathrm{b}}$ & $49(36-63)$ & $49.5(39-60)$ & $0.99(0.97-1.01)$ & 0.214 \\
\hline BMI $\left(\mathrm{kg} / \mathrm{m}^{2}\right)^{\mathrm{b}}$ & $26.0(23.9-28.6)$ & $27.9(24.8-31.0)$ & $0.92(0.86-0.97)$ & 0.005 \\
\hline Smoke $^{\mathrm{a}}\left(\right.$ yes/no) ${ }^{\mathrm{a}}$ & $22 / 34(39.3 / 60.7)$ & $43 / 82(34.4 / 65.6)$ & $1.40(0.82-2.40)$ & 0.216 \\
\hline $\begin{array}{l}\text { Habit of drinking alcohol } \\
\quad(\text { yes/no })^{a}\end{array}$ & $27 / 29(48.2 / 51.8)$ & $73 / 52(58.4 / 41.6)$ & $1.06(0.63-1.81)$ & 0.816 \\
\hline $\mathrm{ESS}^{\mathrm{b}}$ & $8(5-10)$ & $8(5-10)$ & $1.00(0.94-1.06)$ & 0.980 \\
\hline $\begin{array}{l}\text { Nasal airflow resistance } \\
\left(\mathrm{Pa} / \mathrm{cm}^{3} / \mathrm{s}\right)^{b}\end{array}$ & $2.1(0.3-1.2)$ & $0.57(0.4-1.00)$ & $1.04(0.97-1.10)$ & 0.282 \\
\hline $\begin{array}{l}\text { First-month utilization } \\
\quad \text { rate }(\%)^{\mathrm{b} c}\end{array}$ & $70.8(51.1-95.1)$ & $92.8(74.3-100)$ & $0.98(0.97-0.98)$ & $<0.001$ \\
\hline
\end{tabular}

${ }^{a}$ Sex, smoking, and drinking are indicated by the number of cases $(\%)$

${ }^{\mathrm{b}}$ Age, BMI, ESS, and nasal airflow resistance are indicated by the median (interquartile range)

${ }^{\mathrm{c}}$ Nasal airflow resistance was measured at $\triangle \mathrm{P} 100 \mathrm{~Pa}$ with anterior rhinomanometry

BMI body mass index, CPAP continuous positive airway pressure, ESS Epworth Sleepiness Scale be recognized that patients with OSA might discontinue CPAP treatment until 76 months.

Some studies suggest that BMI has no effect on CPAP treatment continuation $[11,12,23]$. However, others suggest that BMI does effect CPAP treatment continuation, and the findings of the present study are consistent with the results of these studies $[13,21]$. One study found that patients with drowsiness had high BMI and proposed that the decrease in drowsiness caused by the application of CPAP treatment would motivate patients to continue CPAP application [13]. Patients with a high BMI may experience the benefits of CPAP treatment more easily. One study comparing obese patients with OSA with non-obese patients with OSA shows that OSA non-obese patients have a lower arousal threshold for airway stenosis, which may limit CPAP resistance and contribute to reduced CPAP compliance [26]. It should be recognized that it may be difficult to treat OSA with CPAP in patients with low BMI.

The utilization of CPAP treatment, i.e., CPAP usage time per night, within 1-3 months after its initiation was associated with long-term CPAP treatment continuation [13, 19]. Although the present study evaluated the usage in days per month (patients with OSA did not use CPAP treatment on a daily basis, except some patients who used it daily), not the usage time per night, the results were similar to those of previous studies. Some patients may feel comfortable with CPAP treatment and others may not [27-29]. For patients who feel uncomfortable with CPAP treatment since its initiation, it is possible that there are fewer days of CPAP application within the first month, and as a result, these patients may discontinue the treatment. In previous studies, the CPAP application pattern was determined within the first few weeks of treatment initiation [13, 23]. This means that patients who apply CPAP less frequently during its initiation will find it difficult to increase the frequency of use later. Our methods to address patients who feel uncomfortable with CPAP include pressure adjustment, nasal closure measures, and/or mask replacement. These interventions should be implemented as early as possible after the initiation of CPAP treatment.

\section{Limitations}

Our study has some limitations because of its single-facility, retrospective design and relatively small sample size. First, we
Table 3 Univariate analysis: Variables affecting dropout of CPAP (OSA parameters)

\begin{tabular}{|c|c|c|c|c|}
\hline PSG & $\begin{array}{l}\text { Patients refusing CPAP } \\
(n=56)\end{array}$ & $\begin{array}{l}\text { Patients accepting CPAP } \\
(n=125)\end{array}$ & $\begin{array}{l}\text { Hazard ratio } \\
(95 \% \mathrm{CI})\end{array}$ & $\begin{array}{l}P \\
\text { value }\end{array}$ \\
\hline AHI (/h) & $47.7(36.1-72.1)$ & $48.3(32.3-76.8)$ & $1.00(0.99-1.01)$ & 0.599 \\
\hline $\mathrm{AI}(/ \mathrm{h})$ & $15.8(7.9-45.2)$ & $19.7(7.8-57.0)$ & $1.00(0.99-1.00)$ & 0.339 \\
\hline $\mathrm{HI}(/ \mathrm{h})$ & $23.2(16.7-32.3)$ & $20.3(11.8-28.3)$ & $1.01(0.99-1.03)$ & 0.215 \\
\hline Minimum $\mathrm{SaO}_{2}(\%)$ & $80(72-84)$ & $77(69-82)$ & $1.03(1.00-1.06)$ & 0.085 \\
\hline $\begin{array}{l}\text { Time }\left(\mathrm{SaO}_{2}<90 \%\right) \\
\quad(\mathrm{min})\end{array}$ & $16.0(8.3-63.3)$ & $28.0(8.6-75.4)$ & $1.00(0.99-1.00)$ & 0.200 \\
\hline
\end{tabular}

The value of each item is indicated by the median value (interquartile range)

AHI Apnea-hypopnea Index, AI Apnea Index, HI Hypopnea Index, CPAP continuous positive airway pressure, $P S G$ polysomnography, OSA obstructive sleep apnea, Time $(\mathrm{SaO} 2<90 \%$ ) time spent with $\mathrm{SaO} 2<90 \%$ 
Table 4 Univariate analysis: Variables affecting dropout of CPAP (CPAP titration)

\begin{tabular}{lllll}
\hline CPAP titration & $\begin{array}{l}\text { Patients refusing CPAP } \\
(n=56)\end{array}$ & $\begin{array}{l}\text { Patients accepting CPAP } \\
(n=125)\end{array}$ & $\begin{array}{l}\text { Hazard ratio } \\
(95 \% \mathrm{CI})\end{array}$ & $\begin{array}{l}P \\
\text { value }\end{array}$ \\
\hline $\mathrm{AHI}(/ \mathrm{h})$ & $6.2(3.8-12.8)$ & $7.2(3.9-9.9)$ & $1.00(0.97-1.04)$ & 0.954 \\
$\mathrm{AI}(/ \mathrm{h})$ & $0.6(0.2-1.7)$ & $0.5(0-1.2)$ & $1.03(0.96-1.11)$ & 0.394 \\
$\mathrm{HI}(/ \mathrm{h})$ & $5.3(3.3-8.4)$ & $5.3(3.4-8.7)$ & $0.99(0.95-1.04)$ & 0.746 \\
$\mathrm{Minimum} \mathrm{SaO}_{2}(\%)$ & $90(88-93)$ & $90(87-92)$ & $1.03(0.97-1.09)$ & 0.403 \\
$\begin{array}{c}\text { Time }\left(\mathrm{SaO}_{2}<90 \%\right) \\
(\mathrm{min})\end{array}$ & $0(0-1.1)$ & $0(0-1.0)$ & $0.96(0.90-1.04)$ & 0.374 \\
\hline
\end{tabular}

The value of each item is indicated by the median value (interquartile range)

AHI Apnea-hypopnea Index, $A I$ Apnea Index, $H I$ Hypopnea Index, $C P A P$ continuous positive airway pressure, $P S G$ polysomnography, OSA obstructive sleep apnea, Time $(\mathrm{SaO} 2<90 \%)$ time spent with $\mathrm{SaO} 2$ of $<90 \%$ did not develop strict classification criteria for continuation/ dropout based on days of CPAP use. Regarding patients with OSA who were experiencing CPAP-related discomfort, we provided support to improve their CPAP-related experience on days of use. We recommended patients with OSA to use CPAP for at least $4 \mathrm{~h}$ for $70 \%$ of the days in a month. However, some patients who were classified as patients accepting CPAP failed to exceed this criterion, either temporarily or continuously. We might have to consider whether they were fit to be classified as patients accepting CPAP. Second, mental and psychological factors may affect final results; however, these factors were not considered in this study. Third, most patients in this study were males; therefore, we cannot exclude the possibility of sex differences. Fourth, as a result of using the Japanese health care system, we only provided CPAP to patients with OSA with an AHI of $>20$; therefore, CPAP adherence among patients with mild OSA remains unknown. A prospective, multi-institutional study involving patients with mild OSA and a higher proportion of women is required.

Finally, the continuation rate for the past 10 years may not coincide with that in the upcoming 10 years following a recent initiation of CPAP treatment. We believe that the current CPAP machine and mask may be better and easier to use than it was 10 years ago. The continuation rate 10 years from now may be better than that reported in this study.

\section{Conclusion}

In this study, the 10-year continuation or discontinuation rate following the initiation of CPAP treatment was confirmed in patients with OSA. Patient's BMI and utilization rate within

Table 5 Multivariate analysis: variables affecting dropout of CPAP

\begin{tabular}{lll}
\hline & Hazard ratio (95\% CI) & $P$ value \\
\hline First-month utilization rate (\%) & $0.97(0.96-0.98)$ & $<0.001$ \\
BMI $\left(\mathrm{kg} / \mathrm{m}^{2}\right)$ & $0.89(0.84-0.96)$ & $<0.001$ \\
\hline
\end{tabular}

$B M I$ body mass index approximately 1 month of the initiation of CPAP treatment are the predictors of long-term CPAP treatment utilization.

Acknowledgments We would like to thank Shintaro Chiba for the useful discussions pertaining to this study.

\section{Compliance with ethical standards}

Conflict of interest The authors declare that they have no conflict of interest.

Research involving human participants and/or animals All procedures performed in studies involving human participants were in accordance with the ethical standards of the institutional and/or national research committee and with the 1964 Helsinki declaration and its later amendments or comparable ethical standards.

Informed consent Formal consent was not required for this study.

Open Access This article is licensed under a Creative Commons Attribution 4.0 International License, which permits use, sharing, adaptation, distribution and reproduction in any medium or format, as long as you give appropriate credit to the original author(s) and the source, provide a link to the Creative Commons licence, and indicate if changes were made. The images or other third party material in this article are included in the article's Creative Commons licence, unless indicated otherwise in a credit line to the material. If material is not included in the article's Creative Commons licence and your intended use is not permitted by statutory regulation or exceeds the permitted use, you will need to obtain permission directly from the copyright holder. To view a copy of this licence, visit http://creativecommons.org/licenses/by/4.0/.

\section{References}

1. Benjafield AV, Ayas NT, Eastwood PR, Heinzer R, Ip MS, Morrell MJ, Nunez CM, Patel SR, Penzel T, Pépin JL, Peppard PE, Sinha S, Tufik S, Valentine K, Malhotra A (2019) Estimation of the global prevalence and burden of obstructive sleep apnoea: a literaturebased analysis. Lancet Respir Med 7:687-698. https://doi.org/10. 1016/S2213-2600(19)30226-7

2. Peppard PE, Young T, Palta M, Skatrud J (2000) Prospective study of the association between sleep-disordered breathing and hypertension. N Engl J Med 342:1378-1384. https://doi.org/10.1056/ NEJM200005113421901 
3. Barbé F, Durán-Cantolla J, Sánchez-de-la-Torre M, MartínezAlonso M, Carmona C, Barceló A, Chiner E, Masa JF, Gonzalez M, Marín JM, Garcia-Rio F (2012) Effect of continuous positive airway pressure on the incidence of hypertension and cardiovascular events in nonsleepy patients with obstructive sleep apnea: a randomized controlled trial. JAMA 307:2161-2168. https://doi. org/10.1001/jama.2012.4366

4. Sánchez-de-la-Torre M, Campos-Rodriguez F, Barbé F (2013) Obstructive sleep apnoea and cardiovascular disease. Lancet Respir Med 1:61-72. https://doi.org/10.1016/S2213-2600(12) 70051-6

5. Jenkinson C, Davies RJ, Mullins R, Stradling JR (1999) Comparison of therapeutic and subtherapeutic nasal continuous positive airway pressure for obstructive sleep apnoea: a randomised prospective parallel trial. Lancet 353:2100-2105. https://doi.org/ 10.1016/S0140-6736(98)10532-9

6. Pepperell JC, Ramdassingh-Dow S, Crosthwaite N, Mullins R, Jenkinson C, Stradling JR, Davies RJ (2002) Ambulatory blood pressure after therapeutic and subtherapeutic nasal continuous positive airway pressure for obstructive sleep apnoea: a randomised parallel trial. Lancet 359:204-210. https://doi.org/10.1016/S01406736(02)07445-7

7. Antic NA, Catcheside P, Buchan C, Hensley M, Naughton MT, Rowland S, Williamson B, Windler S, McEvoy RD (2011) The effect of CPAP in normalizing daytime sleepiness, quality of life, and neurocognitive function in patients with moderate to severe OSA. Sleep 34:111-119. https://doi.org/10.1093/sleep/34.1.111

8. Becker HF, Jerrentrup A, Ploch T, Grote L, Penzel T, Sullivan CE, Peter JH (2003) Effect of nasal continuous positive airway pressure treatment on blood pressure in patients with obstructive sleep apnea. Circulation 107:68-73. https://doi.org/10.1161/01.cir. $0000042706.47107 .7 \mathrm{a}$

9. Craig SE, Kohler M, Nicoll D, Bratton DJ, Nunn A, Davies R, Stradling J (2012) Continuous positive airway pressure improves sleepiness but not calculated vascular risk in patients with minimally symptomatic obstructive sleep apnoea: the MOSAIC randomised controlled trial. Thorax 67:1090-1096. https://doi.org/10.1136/ thoraxjnl-2012-202178

10. Campos-Rodriguez F, Peña-Griñan N, Reyes-Nuñez N, De la CruzMoron I, Perez-Ronchel J, De la Vega-Gallardo F, FernandezPalacin A (2005) Mortality in obstructive sleep apnea-hypopnea patients treated with positive airway pressure. Chest 128:624 633. https://doi.org/10.1378/chest.128.2.624

11. Florés M, Martínez-alonso M, Sánchezde-la-Torre A, Aldomà A, Galera E, Barbé F, Sánchezde-la-Torre M, Dalmases M (2018) Predictors of long-term adherence to continuous positive airway pressure in patients with obstructive sleep apnoea and acute coronary syndrome. J Thorac Dis 10:S124-S134. https://doi.org/10. 21037/jtd.2017.12.128

12. Lee CHK, Leow LC, Song PR, Li H, Ong TH (2017) Acceptance and adherence to continuous positive airway pressure therapy in patients with obstructive sleep apnea (OSA) in a Southeast Asian privately funded healthcare system. Sleep Sci 10:57-63. https://doi. org/10.5935/1984-0063.20170010

13. Luyster FS, Strollo PJ Jr, Thunström E, Peker Y (2017) Long-term use of continuous positive airway pressure therapy in coronary artery disease patients with nonsleepy obstructive sleep apnea. Clin Cardiol 40:1297-1302. https://doi.org/10.1002/clc.22827

14. Furukawa T, Suzuki M, Ochiai M, Kawashima H, Yokoyama N, Isshiki T (2014) Long-term adherence to nasal continuous positive airway pressure therapy by hypertensive patients with preexisting sleep apnea. J Cardiol 63:281-285. https://doi.org/10.1016/j.jjcc. 2013.08.013

15. Baratta F, Pastori D, Bucci T, Fabiani M, Fabiani V, Brunori M, Loffredo L, Lillo R, Pannitteri G, Angelico F, Del Ben M (2017) Long-term prediction of adherence to continuous positive air pressure therapy for the treatment of moderate/severe obstructive sleep apnea. Sleep Med 43:66-70. https://doi.org/10.1016/j.sleep. 2017.09.032

16. Abdelghani A, Benzarti W, Ben Salem H, Gargouri I, Garrouche A, Hayouni A, Benzarti M (2016) Adherence to treatment with continuous positive airway pressure in the obstructive sleep apnea syndrome. Tunis Med 94:551-562

17. Uematsu A, Akashiba T, Kumasawa F, Akahoshi T, Okamoto N, Nagaoka K, Gon Y, Kaneita Y, Uchiyama M, Hashimoto S (2016) Factors influencing adherence to nasal continuous positive airway pressure in obstructive sleep apnea patients in Japan. Sleep Biol Rhythms 14:339-349. https://doi.org/10.1007/s41105-016-0064-8

18. Wang Q, Ou Q, Tian XT, Chen YC, Nie ZQ, Gao XL (2016) Analysis of long-term compliance to continuous positive airway pressure in patients with obstructive sleep apnea. Zhonghua Yi Xue Za Zhi 96:2380-2384. https://doi.org/10.3760/cma.j.issn. 0376-2491.2016.30.004

19. McArdle N, Devereux G, Heidarnejad H, Engleman HM, Mackay TW, Douglas NJ (1999) Long-term use of CPAP therapy for sleep apnea/hypopnea syndrome. Am J Respir Crit Care Med 159:11081114. https://doi.org/10.1164/ajrccm.159.4.9807111

20. Campos-Rodriguez F, Martínez-alonso M, Sánchez-de-la-torre M, Barbé F (2016) Long-term adherence to continuous positive airway pressure therapy in nonsleepy sleep apnea patients. Sleep Med 17: 1-6. https://doi.org/10.1164/ajrccm.159.4.9807111

21. Krieger J, Kurtz D, Petiau C, Sforza E, Trautmann D (1996) Longterm compliance with CPAP therapy in obstructive sleep apnea patients and in snorers. Sleep 19:S136-S143. https://doi.org/10. 1093/sleep/19.suppl_9.S136

22. Kohler M, Smith D, Tippett V, Stradling JR (2010) Predictors of long-term compliance with continuous positive airway pressure. Thorax 65:829-832. https://doi.org/10.1136/thx.2010.135848

23. Campos-Rodriguez F, Martinez-Garcia MA, Reyes-Nuñez N, Caballero-Martinez I, Almeida-Gonzalez CV, Catalan-Serra P, Peña-Griñan N (2013) Long-term continuous positive airway pressure compliance in females with obstructive sleep apnoea. Eur Respir J 42:1255-1262. https://doi.org/10.1183/09031936. 00165812

24. Rechtschaffen A, Kales A (1968) In: Berger RJ, Dement WC, Jacobson A, Johnson LC, Jouvet M, Monroe LJ, Oswald I, Roffwarg HP, Roth B, Walter RD (eds) A manual of standardized terminology, techniques and scoring system for sleep stages of human subjects. Public Health Service, U.S. Government Printing Office, Washington

25. Parish JM, Lyng PJ, Wisbey J (2000) Compliance with CPAP in elderly patients with OSA. Sleep Med 1:209-214. https://doi.org/ 10.1016/S1389-9457(00)00011-3

26. Gray EL, McKenzie DK, Eckert DJ (2017) Obstructive sleep apnea without obesity is common and difficult to treat: evidence for a distinct pathophysiological phenotype. J Clin Sleep Med 13:8188. https://doi.org/10.5664/jcsm.6394

27. Zgierska A, Pietrzyk A, Pływaczewski R, Zieliński J (2000) Compliance to treatment recommendations in patients with obstructive sleep apnea at least one year after diagnosis. Pneumonol Alergol Pol 68:11-20

28. Bachour A, Vitikainen P, Maasilta P (2016) Rates of initial acceptance of PAP masks and outcomes of mask switching. Sleep Breath 20:733-738. https://doi.org/10.1007/s11325-015-1292-x

29. Fleury B, Nguyen XL, Rakotonanahary D, Cohen-Levy J, Pételle B (2009) The set-up of obstructive sleep apnea treatment. Rev Pneumol Clin 65:214-218. https://doi.org/10.1016/j.pneumo. 2009.07.002

Publisher's note Springer Nature remains neutral with regard to jurisdictional claims in published maps and institutional affiliations. 